\title{
Toward the Total Synthesis of (+)-trans-Trikentrin A
}

\author{
Iris R. M. Tébéka, Luiz F. Silva Jr.* \\ Instituto de Química, Universidade de São Paulo, CP 26077 CEP 05513-970 São Paulo - SP, Brazil \\ *luizfsjr@iq.usp.br
}

Keywords: total synthesis, asymmetric synthesis, indole, alkaloid, trikentrin

\section{INTRODUCTION}

The alkaloid (+)-trans-trikentrin $A$ is a marine natural product isolated in $1986^{1}$ whose racemic synthesis has already been achieved by our group ${ }^{2}$ through a ring contraction key step. Herein we describe our recent afforts toward the total synthesis of $(+)$-trans-trikentrin A (Scheme 1).

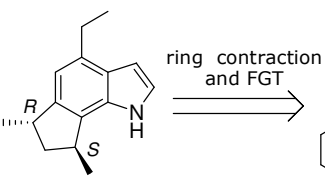

(+)-trans-Trikentrin A

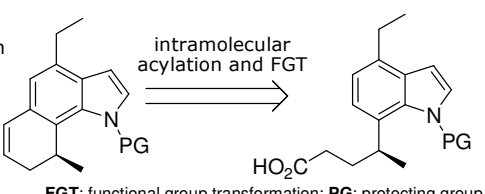

FGT: functional group transformation; PG: protecting group
Scheme 1. Retrosynthesis to (+)-trans-trikentrin A.

\section{RESULTS AND DISCUSSION}

An asymmetric conjugate addition ${ }^{3}$ was our first attempt to define the stereocenter. As it could not be achieved on 2 (Scheme 2), we decided to perform the coupling of a substituted indoline ring (3, Scheme 3) with an iron complex obtained from a lactic acid derivative. ${ }^{4}$ (4, Scheme 4) This coupling would occur in an diastereoselective manner, allowing the synthetic route to be more convergent than the previous approach.

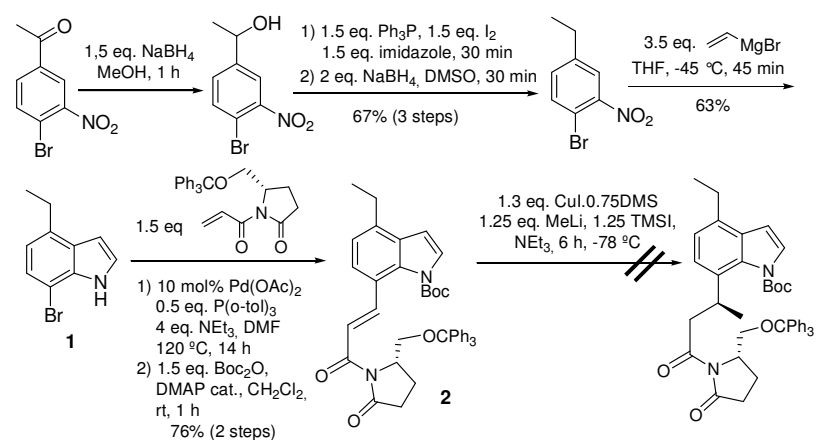

Scheme 2. Preparation of the substrate for asymmetric conjugate addition and unsuccessful trial.

The lithiated product 3 could be formed in situ, and we are now working on the coupling step. In parallel, we are also investigating a kinetic resolution performed by lipase ${ }^{5}$ on the saturated ester 5 as a possible alternative (Scheme 5).
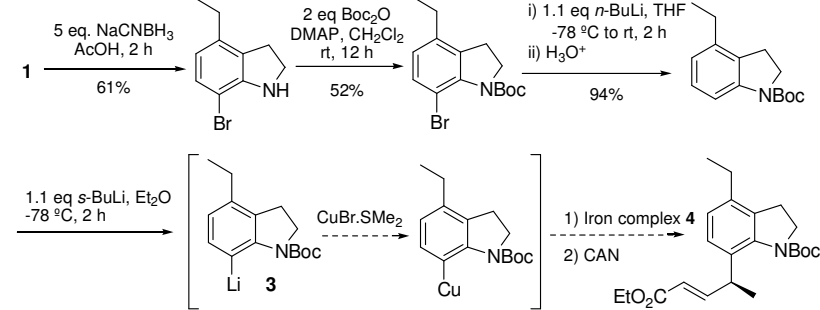

Scheme 3. Preparation of indoline and further coupling.

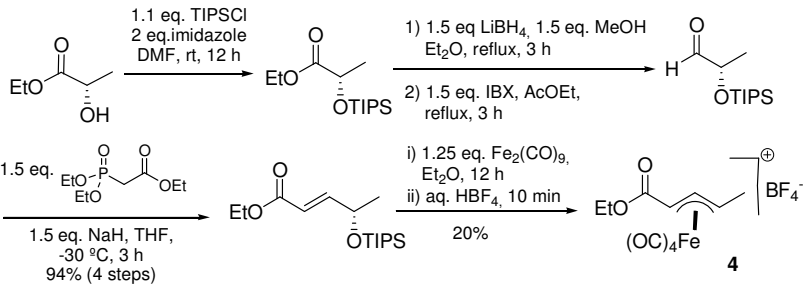

Scheme 4. Preparation of the iron complex 4.

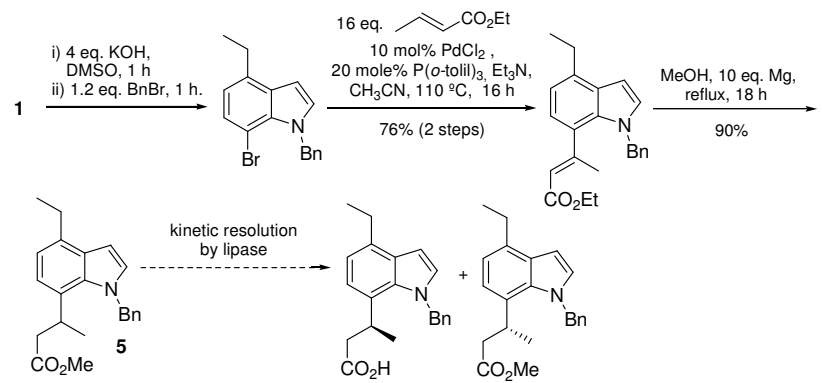

Scheme 5. Preparation of the saturated ester for kinetic resolution.

\section{CONCLUSION}

The first stereocenter of our target molecule could not be achieved by a conjugate addition. A diastereoselective coupling that would lead to a more convergent route is being tested. In parallel, a kinetic resolution of the stereocenter performed by lipase is under investigation.

\section{ACKNOWLEDGEMENTS}

CNPq, Fapesp and CAPES for financial support.

\section{REFERENCES}

${ }_{1}^{1}$ Capon, R. J.; MacLeod, J. K.; Scammels, P. J. Tetrahedron 1986, 42, 6545.

2 Silva, L. F., Jr.; Craveiro, M. V. Org. Lett. 2008, 10, 5417.

${ }^{3}$ Dambacher, J.; Anness, R.; Pollock, P.; Bergdahl, M. Tetrahedron 2004, 60, 2097.

${ }^{4}$ Chow, R.; Kocienski, P. J.; Kuhl, A.; LeBrazidec, J.-Y.; Muir, K.; Fish, P. J.

Chem. Soc., Perkin Trans. 1 2001, 2344.

${ }^{5}$ Paál, T. A.; Forró, E.; Fülöp, F.; Liljebad, A.; Kanerva, L. T. Tetrahedron: Asymmetry 2008, 19, 2784. 